\title{
Turning the Spotlight on Nutritional Status Evaluation: Is it a Newsworthy Idea?
}

\author{
Filomena Pietrantonio* \\ Manerbio Hospital, Italy \\ *Corresponding author: Filomena Pietrantonio, Internal Medicine Unit, Manerbio Hospital, Manerbio (BS), ASST-Garda, Italy
}

Submission: February, 26, 2018; Published: April 19, 2018

Abbreviations: OB: Obesity; BMI: Body Mass Index; GNP: Gross National Product; ICUs: Intensive Care Units; MUST: Malnutrition Universal Screening

Tool, MNA: Mini Nutritional Assessment; SGA: Subjective Global Assessment

\section{Editorial}

Mortality rates among adults has been declining in most countries for decades. Lower rates of death from infectious diseases was the early driver of this improvement, but there have been subsequent declines in mortality from cardiovascular disease and some cancers. The hazardous effects of behavioral and dietary risk factors on non-communicable diseases and the metabolic and physiological conditions that mediate their effects, have been established in prospective cohort studies and randomized trials. This knowledge, together with data from risk-factor surveillance has helped to establish the mortality and disease burden attributable to these risk factors [1]. Recent reviews of the literature on nutrition and hospitalization in patients with non-communicable diseases have highlighted the relationship between obesity, socio-economic status, nutrition, morbidity and mortality, length of hospital stay and related costs. Evidence from the literature shows that although much research has been dedicated to exploring obesity's relationship to risk factors and socioeconomic status, very few studies have been carried out examining obesity in hospitalized patients. Genetic and environmental risk factors are well known. In 2010 a Danish study [2] showed that obesity (OB) is a stable phenomenon in the United States and is on the rise in Europe and Asia, equally affecting both men and women. In a subsequent review, Brisbois [3] identified seven early markers of OB, including smoking during pregnancy, weight gain during pregnancy, maternal Body Mass Index (BMI), childhood obesity and father's job. This data clearly demonstrates the need for early prevention campaigns. A clear relationship between income-obesity and health policies has been demonstrated in developing countries. In fact, with a Gross National Product (GNP) growth of over 2500\$, the increase in obesity affects the lower classes of the population [4]. These data suggests a need for appropriate policies and prevention campaigns. Moreover, consideration of certain determinants of socio-economic status such as wealth, education and employment help pinpoint more vulnerable social groups. Belonging to more disadvantaged social categories favors becoming obese and the obese condition prevents moving up in social status [5,6]. Obesity has been considered an indirect cause of a higher mortality rates, even if recent meta-analyses could not unequivocally confirm this statement [7].

In obese hospitalized patients, on the other hand, longer stays in Intensive Care Units (ICUs) and greater risk of complications have been demonstrated [8]. Indeed, in critical patients evidence exists of increased complication rates, mainly in the Intensive Care Unit. Out of 62,045 patients admitted to the ICU, longer duration of respiratory support and higher inpatient related costs were identified in obese subjects [9]. A study conducted by Wigfield et al. [10] concluded that more frequent complications were only seen in morbidly obese patients (BMI> 40) . Further studies have been performed aimed at assessing nutritional status, on the basis of evidence that increased mortality and greater morbidity and length of hospital stay depends on malnutrition, to which obese patients are equally subject both in terms of micronutrient deficiencies and inadequate muscle mass, representing the so called obesity paradox. Preventive measures could therefore reduce costs for national health systems [11]. Consequently, the assessment of nutritional status on admission to the hospital is key. The nutritional status evaluation tests (Malnutrition Universal Screening Tool-MUST, Mini Nutritional Assessment-MNA, Subjective Global Assessment-SGA) have similar validity and the choice depends on the type of institution, the type of patients and the available resources $[12,13,14]$. Together with the evaluation of nutritional status, careful examination of each patient's habitual diet in the 6-12 months prior to admission is essential and should be assessed using validated questionnaires in order to standardize the data indicating that the costs of malnutrition are indeed rising $[15,16]$. This phenomenon is mainly due to: 


\section{Increased length of stay;}

\section{Increased complexity of treatments.}

Multivariate analyses show that costs for patients at nutritional risk increas by $20 \%$ compared to normal weight patients. A recent study by Cawley [17] on the health care costs of obesity in the United States reported that an obese patient costs $\$ 2,741$ more per year than a normal weight person.

\section{Conclusion}

Analysis of the Literature confirms the lack of data on the relationship between nutritional status and costs related to treatment during hospitalization. Future studies are needed in which comparative analyses of nutritional status on admission are set up to promptly detect nutritional conditions that may affect clinical progress during the hospital stay. Moreover, validated tools already exist to establish patients dietary habits, and their regular use is therefore strongly advisable in order to better understand how much the pre-hospitalization diet affects the evolution of chronic diseases.

\section{References}

1. Ezzati M, Riboli E (2013) Behavioral and Dietary Risk Factors for Noncommunicable Diseases. N Engl J Med 369(10): 954-64.

2. Rokholm B, Baker JL, Sørensen TI (2010) The levelling off of the obesity epidemic since the year 1999- a review of evidence and perspectives. Obes Rev 11(12): 835-846.

3. Brisbois TD, Farmer AP, Mc Cargar LJ (2012) Early markers of adult obesity: a review. Obes Rev 13(4): 347-367.

4. Monteiro CA, Moura EC, Conde WL, Popkin BM (2004) Socio economic status and obesity in adult populations of developing countries: a review. Bull World Health Organ 82(12): 940-946.

5. Fillol F, Dubuisson C, Lafay L, Dufour A, Bertin M, et al. (2011) Accounting for the multidimensional nature of the relationship between adult obesity and socio-economic status: the french second national individual survey on food consumption (inca 2) dietary survey. Br J Nutr 106(10): 1602-1608

6. Sobal J (1991) Obesity and socioeconomic status: a framework for examining relationships between physical and social variables. Med Anthropol 13(3): 231-247.

7. Mehta NK, Chang VW (2009) Mortality attributable to obesity among middle-aged adults in the United States. Demography 46(4): 851-872.

8. Oliveros H, Villamor E (2008) Obesity and mortality in critically ill adults: a systematic review and meta-analysis. Obesity (Silver Spring) 16(3): 515-521.

9. Akinnusi ME, Pineda LA, El Solh AA (2008) Effect of obesity on intensive care morbidity and mortality: a meta-analysis. Crit Care Med 36(1): 151158.

10. Wigfield CH, Lindsey JD, Muñoz A, Chopra PS, Edwards NM, et al. (2006) Is extreme obesity a risk factor for cardiac surgery? An analysis of patients with a BMI>40. Eur J Cardiothorac Surg 29(4): 434-440.

11. Löser C (2010) Malnutrition in hospital: the clinical and economic implications. Dtsch Arztebl Int 107 (51-52): 911-917.

12. Kyle UG, Genton L, Pichard C (2005) Hospital length of stay and nutritional status. Curr Opin Clin Nutr Metab Care 8(4): 397-402.

13. Elia M, Stratton RJ (2012) An analytic appraisal of nutrition screening tools supported by original data with particular reference to age. Nutrition 28(5): 477-494.

14. Amaral TF, Matos LC, Tavares MM, Subtil A, Martins R, et al. (2007) The economic impact of disease-related malnutrition at hospital admission. Clin Nutr 26(6): 778-784.

15. Kondrup J, Sorensen JM (2009) The magnitude of the problem of malnutrition in Europe. Nestle Nutr Workshop Ser Clin Perform Programme 12: 1-14.

16. Norman K, Pichard C, Lochs H, Pirlich M (2008) Prognostic impact of disease-related malnutrition. Clin Nutr 27(1): 5-15.

17. Cawley J, Meyerhoefer C (2012) The medical care costs of obesity: an instrumental variables approach. J Health Econ 31(1): 219-230.
Creative Commons Attribution 4.0

International License

For possible submissions Click Here

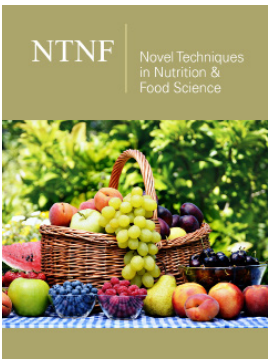

\section{Novel Techniques in Nutrition and Food Science}

\section{Benefits of Publishing with us}

- High-level peer review and editorial services

- Freely accessible online immediately upon publication

- Authors retain the copyright to their work

- Licensing it under a Creative Commons license

- Visibility through different online platforms 